\title{
Article
}

\section{Student perceptions of a healthy university}

Holt, Maxine, Monk, Robert, Powell, Susan and Mark, Dooris

Available at http://clok.uclan.ac.uk/12610/

Holt, Maxine, Monk, Robert, Powell, Susan and Mark, Dooris ORCID: 00000002-5986-1660 (2015) Student perceptions of a healthy university. Public Health, 129 (6). pp. 674-683. ISSN 0033-3506

It is advisable to refer to the publisher's version if you intend to cite from the work. http://dx.doi.org/10.1016/j.puhe.2015.03.020

For more information about UCLan's research in this area go to http://www.uclan.ac.uk/researchgroups/ and search for < name of research Group>.

For information about Research generally at UCLan please go to http://www.uclan.ac.uk/research/

All outputs in CLoK are protected by Intellectual Property Rights law, including Copyright law. Copyright, IPR and Moral Rights for the works on this site are retained by the individual authors and/or other copyright owners. Terms and conditions for use of this material are defined in the policies page.

\section{CLoK}

Central Lancashire online Knowledge www.clok.uclan.ac.uk 
Title: Student Perceptions of a Healthy University

Authors: Maxine Holt, Robert Monk, Susan Powell, Mark Dooris

\begin{abstract}
As complex environments within which individuals and populations operate, universities present important contexts for understanding and addressing health issues. The healthy university is an example of the settings approach, which adopts a whole system perspective, aiming to make places within which people, learn, live, work and play supportive to health and wellbeing. The UK Healthy Universities Network has formulated an online toolkit, which includes a self-review tool, intended to enable universities to assess what actions they need to take to develop as a healthy university. This paper presents findings from consultative research undertaken with students from universities in England, Scotland and Wales, which explored what they believe represents a healthy university.
\end{abstract}

\title{
Methods
}

Student surveys and focus groups were used to collect data across eleven universities in England, Scotland and Wales. A priori themes were used to develop our own model for a healthy university, and for the thematic coding phase of analysis.

\section{Findings}

A healthy university would promote student health and wellbeing in every aspect of its business from its facilities and environment through to its curriculum. Access to reasonably priced healthy food and exercise facilities were key features of a healthy university for students in this study. The Self Review Tool has provided a crucial start for universities undertaking the journey towards becoming a healthy university. In looking to the future both universities and the UK Healthy Universities Network will now need to look at what students 
want from their whole university experience, and consider how the Self Review Tool can help universities embrace a more explicit conceptual framework.

\section{Conclusion}

The concept of a healthy university that can tailor its facilities and supportive environments to the needs of its students will go some way to developing students who are active global citizens and who are more likely to value and prioritise health and wellbeing, in the short and long term through to their adult lives. 


\section{Introduction}

Ecological models of health are inclusive health promotion frameworks that are multilayered. They focus on the influence of environments, policies and other structural factors on health and wellbeing - both directly and through supporting individuals and populations to make informed health-related choices in their daily lives. ${ }^{1}$ The common strand that links these ecological models of health is an emphasis on assets within human systems (for example organisations and communities), which improve health and health outcomes. ${ }^{2}$ As complex environments within which individuals and populations go about their daily lives, universities present rich contexts for understanding and addressing health issues, using approaches drawn from the ecological model of health. The healthy university represents an example of the settings approach, which takes an ecological whole system perspective, aiming to make places within which people, learn, live, work and play supportive to health and wellbeing. ${ }^{3}$ Within the UK, there are 162 Higher Education Institutes (HEIs) with approximately 2.5 million students and more than 378,000 staff. ${ }^{4,5}$ In 2004, the UK Labour Government's Public Health Strategy highlighted the importance of the healthy universities approach, suggesting that this:

Integrates health into the organisation's structure to create healthy working, learning and living environments, increase the profile of health in teaching and research, and develop healthy alliances in the community. ${ }^{6}$

In 2010, the UK Coalition Government endorsed this approach, stating that:

The Healthy Schools, Healthy Further Education and Healthy Universities programmes will continue to be developed by their respective sectors, as voluntary programmes $^{7}$. 
A healthy university (HU) is one which aspires to create a learning environment and organisational culture that enhances the health, wellbeing and sustainability of its community and enables people to achieve their full potential ${ }^{8}$. The healthy university approach also includes consideration of both higher education and public health drivers such as inequalities, alcohol and drug misuse, mental well-being, obesity, sexual health, sustainability, food and physical activity ${ }^{4}$.

In England, there has been a Healthy University Network since 2006. This Network facilitates representatives from HEIs wishing to implement the healthy university approach, to come together to share good practice. This Network has subsequently expanded to encompass all the UK. Between 2009 and 2012, six HEIs from the Network led a collaborative research project entitled Developing Leadership and Governance for Healthy Universities $^{8}$. One of the key outputs of this research was an on-line toolkit including a selfreview tool (http://www.healthyuniversities.ac.uk/assessment/login.php) which, when completed, describes where a HEI needs to focus its attention to develop as a healthy university.

Manchester Metropolitan University (MMU) used the self review tool to complete a selfassessment with senior staff across all university departments and faculties. Whilst the results from the exercise were encouraging, it was recognised that the success of a HU lies in a whole university approach. It was felt therefore, that the self-assessment tool, and its' guiding themes, were useful for those at senior staff level, but that the student voice was not sufficiently captured. In order to achieve a meaningful self-assessment, MMU decided to consult further with students, using the self-assessment tool themes as a guide, to establish the student perceptions of what constitutes a healthy university. 


\begin{abstract}
Aims of the study
This consultative research study aimed to explore and develop an understanding of student perceptions of a healthy university. This could then be used to inform the development of the healthy universities initiative nationally and to support MMU, and other HEIs, in the healthy university journey. The Faculty of Health, Psychology and Social Care Ethics Committee at MMU granted ethical approval for the research.
\end{abstract}

\title{
Methods
}

\section{Data Collection}

Two methods of data collection were used. Firstly, opportunistic student surveys asked students to complete in writing, the sentence 'a healthy university is one which'. Secondly, focus groups explored students' perceptions further. Focus group students were asked to bring a visual object that, for them, represented a healthy university. This object acted as an icebreaker and stimulated discussion. The pairing of narrative and visual tools is becoming a recognised method for assisting the researcher in documenting and symbolizing the selfrepresentations of participants 9 ; i.e. every picture tells a story. Semi-structured questions were used as focus group prompts as follows:

- Please could you tell me about the object you have brought along to the focus group?

- Why does the object you have brought in represent a healthy university to you?

- What do you notice immediately when you walk into a university?

- What do you think a healthy university is?

- What would be present within a unhealthy university?

- What are the most important of these?

\section{Sampling Method}

An expression of interest to participate was circulated via the UK Healthy Universities Network, to healthy university co-ordinators and relevant staff in Student Services 
departments and Students' Union in England, Scotland and Wales. Eleven universities participated in the study (England $n=7$, Scotland $n=2$ and Wales $n=2$ ). The HEIs participating were of varying size and geographical spread. Data were gathered from 423 students studying on a variety of programmes (Business and Law, Science and Engineering, Education, Health, Psychology and Social Care, Arts, Apparel, Food and Tourism , Humanities, Languages and Social Sciences ) through on-site opportunistic student surveys $(n=367)$ and six student focus groups $(\mathrm{n}=56)$.

\section{Analysis}

The benefit of research that both deductively stems from theory and inductively generates theory is reported as being a preferable combination ${ }^{11}$. In this research, a set of a priori key themes were used to develop a model for a healthy university (Figure 1). A priori themes arise from previously agreed definitions, literature and constructs ${ }^{9,10}$. The model described here is derived from the frameworks for a healthy university, identified in an earlier report and from the themes of the self-review toolkit ${ }^{8}$. Responses were transcribed and using the $a$ priori themes, were coded thematically. This enabled further sub-themes to be generated and refined using a form of thematic networks, or web-like illustrations (Figure 2) that summarize the main themes ${ }^{12}$. 
Figure 1: The Healthy University Model

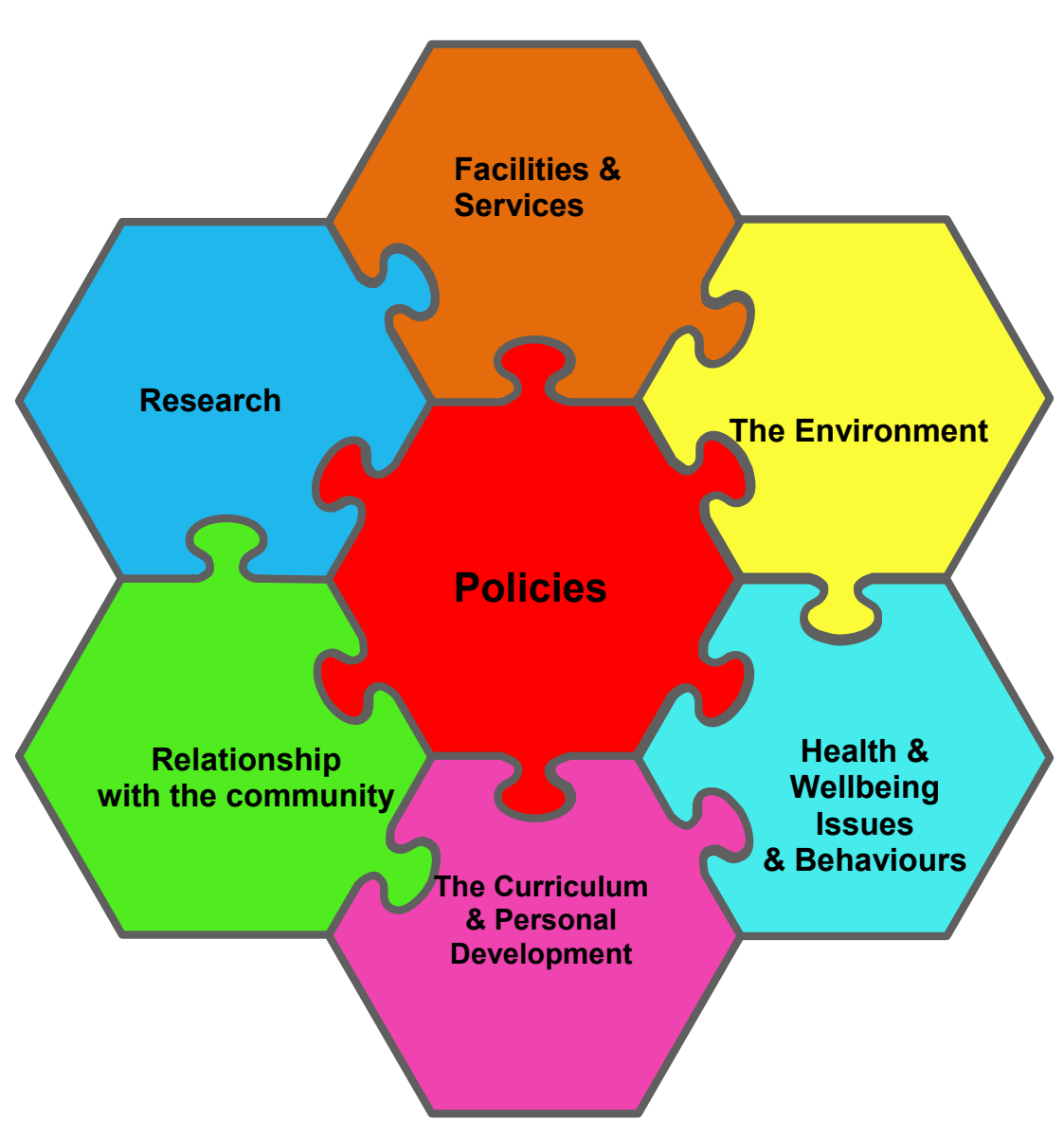




\section{Findings}

Findings from the research are presented below using the a priori key themes and networks of sub-themes with unedited data fragments as illustrators.

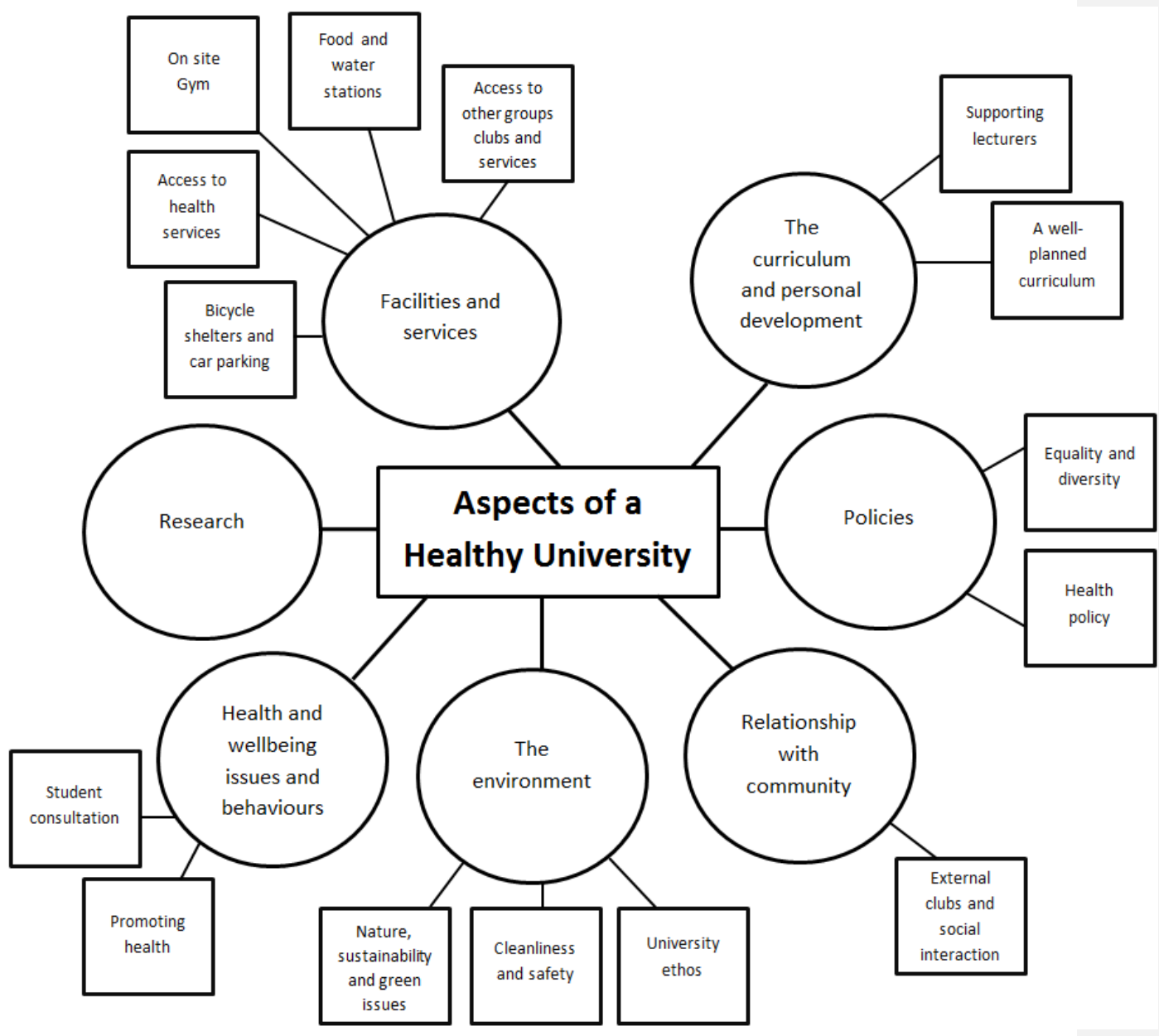

Figure 2: Thematic Networks 


\section{Facilities and Services}

\section{Food and Water Stations}

Access to a variety of healthy, reasonably priced food was a predominant feature for students across all universities. Students believed that a healthy university needs to have:

A wide selection of healthy food and drinks that suit everyone's needs, such as low fat, salt, gluten and wheat free, wider selection of vegetarian foods other than sandwiches and salad. All at affordable student prices (Nutrition student).

A wide range of healthy meals. Fruit available to buy or be free. Not loads of chocolate and cakes. Nutritional information for meals on food and food stands so we know what we are choosing (Mathematics PGCE student).

Those students who participated in focus groups brought along objects such as a piece of fruit to illustrate the need for more fruit options in their university:

Free apples in class would be neat too (English Literature student).

Others brought photos of campus shops or refectories to illustrate examples of healthy or unhealthy options in relation to food choices. Students believed that there should be a responsibility to highlight those foods, which are considered healthy, and those, which are not - and that a healthy university: 
Should focus on] food that would be considered as part of a healthy lifestyle, but with caution displayed for foods that are less healthy (Art and Design PGCE student).

Provides enough healthy options e.g. GM coffee stands only sell chocolates and crisps whereas a fruitier option would be great (History student).

Students discussed the cost of university food, in particular the lower cost of unhealthy foods, such as sweets and chocolate, compared to the cost of healthy foods such as fruit:

The cheaper food options are mainly the unhealthy ones. The chocolate is always cheaper than the fruit (History Student).

A chocolate bar costs 50p and a banana is 70p in our refectory. It's about the physical price of things as well (Speech Therapy student).

A number of students in the focus groups brought bottles of water to highlight what they considered to be an important feature of a healthy university. The key point was the need for free water stations alongside that of healthy food options. Some of the universities did not provide these and in others, this was limited. Bottled water was seen as an unreasonable and expensive food item for students to buy because of their limited budgets. Many students felt that if universities responded to these issues, then they would be more likely to purchase food on campus: 
Currently most students eat out but it would be cheaper and more convenient if good and healthy food was available here (Law Student).

Students recognised that they often ate unhealthy foods when stressed. They highlighted the need for healthy food to support staying healthy during examination and assessment times. They believed that if healthy foods were more readily available and this was supported by encouraging health messages from the university, then they were more likely to eat healthily during times of stress.

\section{Access to other Groups, Clubs and Services}

Commented [MTD1]: You don't need this header any more, as the sub-themes are incorporated under Facilities and Services

\section{On -Site Gym}

The provision of an on-site gym or reduced price student gym membership was considered an important feature of a healthy university. Students discussed this in terms of raising the profile of exercise as a means of supporting student health:

Make exercise a concern/priority of student health (Business Management student).

Give the students opportunities to be involved in exercising including affordable gym membership, sports societies and clubs (Textiles Student).

Free fitness classes/sports sessions - use some of the $£ 9000$ fees we now pay (Secondary PGCE student). 
Access to a gym was also considered by many students to be a significant means of developing relationships and social networking. Students who participated in a focus group brought pictures of groups of students socialising through activities such Zumba and yoga classes. Students who were not necessarily considered to be 'sporty' would join the gym or other types of sports/recreational clubs as a means of meeting other students and making friends. This was particularly important to those students who were living away from home for the first time:

\footnotetext{
A healthy university is one, which has a number of clubs, which people can go and do sport, and keep fit (History student).

It needs to have different ways of exercising and different activities where to meet new people and socialise (Youth and Community Student).

It provides all students with opportunities to take part in recreational activities and sports, catering for all abilities and providing equal opportunities (Chemistry student).
}

\section{Bike Shelters and Car Parking}

Students also brought pictures of bike shelters, which they considered a healthy university, should provide in order to promote both exercise and security: 
'I think there should be a more secure lock up for bicycles as well, because that is one thing that deters me from cycling here. I think if you want to promote cycling (which is obviously healthy) then there should be provisions made (Psychology student).

Car parking was not considered an important feature of a healthy university, as this was seen as encouraging an unhealthy lifestyle and an unnecessary expense.

\section{Access to Health Services}

The need for convenient and efficient access to health services was considered an important characteristic of a healthy university. Students believed that these should be appropriate to student needs and should be on campus, or very close by:

[A healthy university] ensures its students are provided with all basic health-related treatments and medicines when required. Also, it is important to provide an efficient service to students. One where needs and requirements of students are prioritised based on the illness or treatment needed. If treatments are unavailable on campus, a secondary service should be provided (History student).

Others would like to see the provision of nurse led clinics run on a regular basis as a drop in type approach:

[A healthy university] facilitates monthly nurse check-ups for any possibilities of health issues or discussion of health (Law student). 


\section{Policies}

\section{Equality and Diversity}

Students discussed healthy university policies predominantly in terms of healthy food options (linking to Facilities), or the university needing to be a safe place to study and live (linking to Environment). Others believe a healthy university would meet all the regulations for inclusion, recognising the diversity of its student population:

\footnotetext{
A healthy university should respect all individual needs and welcome varied cultures, religions and socio-economic backgrounds. All students should be treated equally, giving everybody the same opportunities (Chemical Engineering).
}

A healthy university should be one which consults with its students, communicates effectively and, where necessary adapts to change:

[It] responds to criticism, adapts to individual needs and leads the way constructing and implementing the latest government strategies (Medical Genetics student).

\section{Health Policy}

These government strategies related to both education and health strategies and students suggested that a healthy university:

Ensures health underpins all its policy and activities (Nursing student). 
Doesn't outright go against the conventions of the day (smoking etc) but instead aims to educate (History student).

A healthy university would ensure that its policies encouraged and provided incentives for students to be healthy. These incentives were understood to include the provision of healthy food options and free drinking water, as previously highlighted. A balance between the core educational focus and the health and wellbeing of students was emphasised:

\footnotetext{
A Healthy university is willing to share its financial wealth in order to establish that students are experiencing their peak spiritual, emotional, and physical health (Diagnostic Imagery student).
}

Many students discussed the need to ensure that university policy ensured the most up-todate equipment was provided for student academic studies. It was felt that this was an expectation particularly with the increases in course fees.

\section{The Environment}

\section{University Ethos}

The environment as a key theme of a healthy university was characterised by students in terms of the overall ethos of a university. Students discussed the feeling or general atmosphere of the university that they experienced at the onset: 
Has a warm and friendly atmosphere so students want to attend, teachers who are there to support their students when possible and one where students and teachers are respected and feel comfortable being around each other (Fashion student).

These first impressions were important in helping students choose their university, and key to this was the way in which university staff, in particular tutors, present themselves as being calm, friendly and supportive. It was suggested that a healthy university:

Has a warm, welcoming and friendly environment with all staff being approachable and willing to help (Engineering student).

Alongside this, one language student suggested that a healthy university is one that:

Gets people smiling.

\section{Cleanliness and Safety}

According to the students in this study, a healthy university is one which is clean, comfortable and safe. This was extended to both university buildings and student residential areas:

A healthy university would also ensure that hygiene and cleanliness is a priority to ensure it is a safe place to work, live and study (Social Science student). 


\section{Nature, Sustainability and Green Issues}

The location of the campus buildings and green issues were discussed in terms of buildings being well lit and having natural daylight to promote a sense of wellbeing:

We are very fortunate to be next to a park and just that sense of greenness and sky just makes it feels a healthier place to be (Engineering student).

A healthy university would effectively prepare students as global citizens who consider the importance of issues such as recycling, and the need to live and work in harmony with each other:

Has pride in the environmental factors that affect the world and encourage us to use bins and has no smoking areas all over campus (Theatre student).

It also takes into account social, financial, mental, religious, ethical, and moral factors of individuals into account to create a harmonious environment (Sport Science student).

A healthy university will provide an environment for these behaviours to be easily carried out (Law student).

\section{Health and Wellbeing Issues and Behaviours}

\section{Promoting Health}

Health and wellbeing was discussed in terms of the ability to eat healthily and to exercise. A healthy university would promote and encourage positive health and wellbeing: 
It offers sustainable and diverse opportunities that support and enhance the health and wellbeing of students and staff alongside their academic study (Occupational Therapy student).

Takes care of the physical and mental health and wellbeing of the individual so that they can achieve the best their ability can allow (Medical Genetics student).

Students discussed the need for health promotion activities and interventions that regularly: Informs me of how I can live healthy every day and helps me when I feel like I need help. Especially when stressed, depressed or burned out (Business Management student).

Students believe that a healthy university would have health promotion as a fundamental feature of its business and that simply providing resources and facilities is, on its own, not enough:

It is not just enough to have the facilities in place. Care must be taken to ensure that people are aware of these facilities and they must be encouraged and guided in order to use them (Business Management student).

\section{Student Consultation}

There was also a belief that a healthy university should reflect its commitment to wellbeing through inclusive processes. Specifically, it was felt that it would consult with students about what makes them healthy and what they need to succeed: 
Allowing the opportunities for individuals to define what makes them feel healthy through activities of all types helps to create an environment to theoretically prosper (History student).

\section{The Curriculum and Personal Development}

\section{Supporting Lecturers}

Students suggested that a healthy university according to the students in this study would have outstanding lecturers, who were able to support students with both academic and personal development through the curriculum:

It would offer a whole package from academia to personal (Psychology student).

The ability to allow staff the time and resources to support students was considered crucial to the achievement and success of students in their academic work and progression to future employment:

[A healthy university] has a high amount of contact hours without jeopardizing the teaching staffs' ability or mental stability (Marketing student).

\section{A Well-Planned Curriculum}

The need for a well-planned curriculum was important where both students and staff have the time to: 
Listen to students about their day-to-day life and wellbeing. The problems they have with settling down to university life, being there for them to offer advice, not to judge (Culture Studies student).

[A healthy university] Has a student interest deep at heart and strives to give the students the best education possible with the greatest chance of employment once finished (Physics student).

Students believed that a healthy university would promote health through its curriculum with tutors facilitating healthy messages through the curriculum. Many students felt that this was the best way to ensure that students know what services and activities were available to them:

Lecturers need to promote health in lectures and encourage students to be healthy.

They are not there just to teach the subject (Pharmaceutical student).

Students highlighted that a healthy university would provide a value-for-money curriculum resulting in a healthy all-round person, who is able to take their place in society.

\section{Relationship with the Community}

\section{External Clubs and Social Interaction}

Community links were discussed mainly in terms of providing students with access to external clubs and groups to facilitate social interaction - it being proposed that a healthy university: 
Would provide good choice of clubs and societies for students to take part in, to help them feel more involved with the university (Psychology student).

Would encourage active participation within the university social experience, whether it be with sports teams, societies or social groups. These not only promote a healthy mentality with the people involved in the programmes but also those outside (Social Science student).

Others made links to extracurricular activities to develop additional skills in helping students become involved in community groups and volunteering. Some students felt that a healthy university should be a community of its own, developing its own characteristics and ethos:

It would feel like a community as opposed to a cold organisation (Law student).

\section{Research}

Research was not identified as a specific characteristic of a healthy university for students in this study. It tended to be classified as having excellent and knowledgeable lecturers and a contemporary curriculum. Undergraduate students did not feel that the research profile of the university would influence their choice of university. These students tended to look at issues discussed thus far in this paper such as facilities and tutor support. 


\section{Discussion}

Encouraging universities to become healthier settings is gaining impetus at national and regional levels. The ideology of a healthy university aligns with higher education priorities such as student experience. It also offers a mechanism to engage with and support a number of major UK Government agendas such as obesity and sustainability ${ }^{13}, 14$. The aim of this exploratory study was to investigate what students, across several different universities in the UK, believe represents a healthy university. It should be acknowledged that data drawn from this qualitative study may not be generalised to the overall UK student population. However, the data provide illustrations of what students perceive as the important features of a healthy university, which may be used to further inform a self-review process.

The focus of other national projects such as the National Healthy School Programme ${ }^{15}$, the Food for Life Partnership, transforming food cultures in schools and school programmes to increase student participation in physical activity ${ }^{16}$, means that students come to university with a set of values that are important to them, their health and their academic performance. It is therefore not surprising that all the students were able to articulate their opinions about the important features of a health university. However, once entering university these features are sometimes overridden by other factors. For example, their choice of food and their ability to eat a healthy diet is influenced by financial pressures that students now face ${ }^{17}$. The main issue for students in this study was not their ability to choose healthy foods, but the cost and availability of healthy foods on campus. This raises important issues for universities in meeting student need and expectations. For example, the availability of free water through water fountains is a multifaceted issue related to both health and sustainability ${ }^{18,19}$ and presents a dichotomy for healthy universities as often water is sold by catering facilities and represents a significant source of revenue. Insight from the researcher was that sustainability, 
in reducing the number of plastic bottles and that of free water fountains was, in this study, more inexplicit in student responses than explicit.

Within the undergraduate population specifically, providing information, which is directly relevant to their lifestyle, is effective ${ }^{20}$. Healthy universities could target students by providing information on how to prepare healthier food quickly and cheaply. Some students find difficulties in continuing with exercise or sport when they go to university due to the absence, of high quality sports provision offered by universities ${ }^{21}$. A healthy university would need to consider its responsibilities in adapting and providing sports facilities to promote active lifestyles for all students. It would need to take into account internal barriers that university student's face such as proximity and cost of sports facilities 22,23 .

The physical and mental health needs of university students are complex and comprise a wide range of aspects 24,25 . Despite raised health awareness amongst university students; their use of health services is reported as relatively low across the university sector in the $\mathrm{UK}^{26}$.

Therefore, a healthy university can benefit by undertaking a health needs assessment so that the specific health and wellbeing needs of their own student population are understood and responded to appropriately ${ }^{27}$. Furthermore, a supportive curriculum that through its content promotes student health and wellbeing and prioritises the development of students as global citizens, would be an additional means of addressing these issues.

Whilst this paper has raised some important issues for those universities wishing to become a healthy university, it is also important to look at the implications for future work for the UK Healthy Universities Network ${ }^{8}$. One of the difficulties is that whilst the settings approach in general and Healthy Universities in particular have been subject to a degree of conceptual 
development, they lack an explicit theoretical framework to guide policy, practice and research ${ }^{28}$. In this context, the Self-Review Tool ${ }^{8}$ has provided a crucial start for universities undertaking the journey towards becoming a healthy university. In looking to the future, both universities and the UK Healthy Universities Network ${ }^{8}$ will now need to look at what students want from their whole university experience, and consider what the Self Review Tool can do to guide the process and to support the development of a more explicit conceptual framework.

\section{Conclusion}

When HEIs complete the Self Review Tool, they receive a 'traffic light' report highlighting areas that require attention for them to progress on their healthy university journey. When engaging with the tool, staff at MMU felt that the student voice required strengthening - and so decided to undertake this research.

The study explored and sought to develop an understanding of student perceptions of a healthy university, using an a priori thematic model to identify the issues of most importance to students. Sub-themes generated through data collection and analysis included food and water stations; equality and diversity; on-site gyms; proactively promoting health; access to health services; overall university ethos; external clubs and social interaction; and several aspects of the environment and curriculum development. Research was not identified as a freestanding theme of importance.

For HEIs, the concept of a healthy university that can tailor its facilities, services, environment and overall 'offer' to the needs and expectations of its students will not only support its own institutional objectives relating to an enhanced student experience, but will 
also contribute to the development of students who are active global citizens - able to value and prioritise their own health, the health of others and wider societal and planetary wellbeing, both in the short term and in their future lives and roles within families, workplaces and communities.

For umbrella bodies seeking to support and facilitate the healthy universities approach, the research findings suggest that it is important and valuable to find ways to engage with, listen to and respond to the student voice. For the UK Healthy Universities Network specifically, it may be valuable to revisit the Self Review Tool and consider whether its content and/or process of implementation could benefit from refining to ensure that student perspectives and views are fully incorporated. 


\section{References}

1. Townsend T, Foster C (2011) Developing and applying a socio-ecological model to the promotion of healthy eating in the school. Public Health Nutrition, pp1-8.

2. Krieger N (2001) Theories for Social Epidemiology in the $21^{\text {st }}$ Century: an ecosocial perspective. International Journal of Epidemiology 30, pp668-677.

3. Dooris M, Doherty S (2010) Healthy universities - time for action: a qualitative research study exploring the potential for a national programme. Health Promotion International, Vol. 25 No.1, pp94-106.

4. Universities UK (2013) Higher Education in Facts and Figures: Summer 2013. London: UUK.

5. Higher Education Statistics Agency (HESA) (2013) Headline Statistics. Cheltenham: HESA. [www.hesa.ac.uk - accessed 21 October 2013]

6. Department of Health (2004) Choosing Health: Making Healthy Choices Easier. London: DH.

7. Department of Health (2010) Healthy Lives, Healthy People. London DH.

8. Healthy Universities Network, England (2010) Model and Framework Project. www.healthyuniversities.ac.uk.

9. Pink S (2001) Doing visual ethnography: Images, media and representation in research. Thousand Oaks, CA: Sage Publications.

10. Maxwell JA (2005) Qualitative research design: An interactive approach (2nd ed.).Thousand Oaks, CA: Sage.

11. Bowling A. (2002) Research Methods in Health: Investigating Health and Health Services, $2^{\text {nd }}$ ed. Buckingham: Open University Press.

12. Attride-Stirling J (2001) Thematic networks: an analytic tool for qualitative research. Qualitative Research, 1 pp385-405.

13. Department of Health (2007) Foresight - Tackling Obesities - Future Choices. London: 
14. Department of Health (2008) Expert Group on Climate Change and Health in the UK. Health Effects of Climate Change. London: Department of Health.

15. Department for Education \& Skills (2004) Healthy Living Blueprint for Schools, DfES/0781/2004

16. Dobbins, M., Lockett, D., Michel, I., Beyers, J., Feldman, L., Bohra, J. and Micucci, S. (2001) The effectiveness of school-based interventions in promoting physical activity and fitness among children and youth: a systematic review. Ontario: McMaster University.

17. Sodexo (2014) The Sodexo University Lifestyle Survey. London.

18. Popkin BM, D'Anci KE, Rosenberg IH (2010) Water, hydration, and health. Nutritional Review, 68(8), pp438-58.

19. Gleick PH, Cooley HS (2009) Energy implications of bottled water. Environmental Research Letters, 4.

20. Pires GN, Pumerantz A, Silbart LK, Pescatello LS (2008) 'The influence of a pilot nutrition education program on dietary knowledge among undergraduate college students'. Californian Journal of Health Promotion, 6(2), pp12-25.

21. Gómez-López M, Granero Gallegos A, Baena Extremera A (2010) Perceived barriers by university students in the practice of physical activities. Journal of Sports Science and Medicine 9, pp74-381.

22. Reed JA, Phillips A (2005) Relationships between physical activity and the proximity of exercise facilities and home exercise equipment used by undergraduate university students. Journal of American College Health 53,pp285-290.

23. Reed JA (2007) Perceptions of the availability of recreational physical activity facilities on a university campus. Journal of American College Health 55, pp189-194.

24. El Ansari W, Stock C (2010) Is the health and wellbeing of university students associated with their academic performance? Cross sectional findings from the United Kingdom. International Journal of Environmental Research in Public Health. 7, pp509-527.

25. Mikolajczyk RT, Brzoska P, Maier C, Ottova V, Meier S, Dudziak U, Ilieva S, El Ansari, W (2008) Factors associated with self-rated health status in university students: A cross-sectional study in three European countries. BMC Public Health 8, p215. 
26. El Ansari W, Stock C, the UK Student Health Group: Snelgrove S Xiaoling Hu, Parke S, Davies S, John J, Hamed Adetunji, Stoate M, Deeny P, Phillips C, Andi Mabhala (2011) International Journal of Environmental Research and Public Health, 8, pp1308-1323.

27. Vo, T, Erskine, S., Cameron, I (undated) Leeds Student Health Needs Assessment. Leeds: Leeds PCT

28. Dooris M, Wills J, Newton J (2014) Theorising Healthy Settings: a critical discussion with reference to Healthy Universities. Scandinavian Journal of Public Health. 